\title{
lodine intake level and incidence of thyroid disease in adults in Shaanxi province: a cross-sectional study
}

\author{
Zhiwei Yu ${ }^{1 \#}$, Yaocheng Yu ${ }^{1 \#}$, Yi Wan ${ }^{2}$, Jing Fan ${ }^{1}$, Huimin Meng ${ }^{1}$, Songpeng Li ${ }^{1}$, Yidi Wang ${ }^{1}$, Ting Wang ${ }^{1}$, \\ Rui Ling ${ }^{1}$
}

${ }^{1}$ Department of Thyroid, Breast and Vascular Surgery, Xijing Hospital, Fourth Military Medical University, Xi'an, China; ${ }^{2}$ Department of Heaepartment of Health Services, Health Service Training Base, Fourth Military Medical University, Xi'an, China

Contributions: (I) Conception and design: T Wang, R Ling; (II) Administrative support: T Wang, R Ling; (III) Provision of study materials or patients: Z Yu, Y Yu, J Fan, H Meng; (IV) Collection and assembly of data: Z Yu, Y Yu, S Li, Y Wang; (V) Data analysis and interpretation: Z Yu, Y Yu, Y Wan; (VI) Manuscript writing: All authors; (VII) Final approval of manuscript: All authors.

\#These authors contributed equally to this work.

Correspondence to: Ting Wang, MD, PhD; Rui Ling, MD, PhD. Department of Thyroid, Breast and Vascular Surgery, Xijing Hospital, Fourth Military Medical University, Xi'an, China. Email: ting_w100@126.com; Lingrui0105@163.com.

\begin{abstract}
Background: Exploring the relationship between adult iodine intake level and thyroid disease in Shaanxi area is of great significance for adult scientific iodine supplement and individual iodine supplement strategy. At present, the relationship between iodine and incidence of thyroid disease has not been determined.

Methods: This study was based on the clinical data of 1,159 patients from the Shaanxi Province aged over 18 years and diagnosed with thyroid-related diseases who were admitted to the Xijing Hospital from 2016 to 2020, and 182 provincial healthy volunteers aged over 18 years who agreed and signed informed consent for physical examination in 2020. The chi-square test and nonparametric test were used to investigate the relationship between iodine intake level and thyroid disease.

Results: (I) A total of 1,341 patients were enrolled and observed in this study. The median urinary iodine (MUI) was $233.20 \mathrm{ug} / \mathrm{L}$. Compared with the control, group participants the urine iodine (UI) of those with hyperthyroidism, Hashimoto's thyroiditis (HT), papillary thyroid cancer (PTC), and benign nodules was significantly different $(\mathrm{P}<0.05)$. (II) The incidence of PTC was higher in women with excessive iodine intake and people aged $\geq 45$ years $(\mathrm{P}<0.05)$. (III) There was no significant difference in urinary iodine (UI), age, gender, and other factors between benign nodules and PTC $(\mathrm{P}>0.05)$.

Conclusions: The iodine intake level of adults in Shaanxi is high, which is related to hyperthyroidism, HT, benign nodules, thyroid cancer, and other diseases. There were 3 factors, including excessive iodine intake, age $\geq 45$ years, and female gender, found to be associated with the development of PTC.
\end{abstract}

Keywords: Iodine intake level; urinary iodine (UI); thyroid disease; papillary thyroid cancer (PTC)

Submitted Aug 26, 2021. Accepted for publication Oct 13, 2021.

doi: $10.21037 / \mathrm{atm}-21-4928$

View this article at: https://dx.doi.org/10.21037/atm-21-4928

\section{Introduction}

Iodine is closely related to human health, with insufficient or excessive iodine intake leading to thyroid diseases. Iodine is an important synthetic raw material for the synthesis of thyroxine in the human body, which is closely related to human health. Both iodine deficiency and excess lead to thyroid diseases. The thyroid has a certain capacity for adjustment, within a certain range of iodine deficiency or iodine excess normal thyroid function can be maintained; when iodine intake exceeds the adaptive capacity of the thyroid, some people will manifest disease, with hypothyroidism may occur due to the thyroid losing its inhibitive ability. In the middle of the last century, as it became apparent that inadequate iodine intake could 
lead to an increase in the incidence of endemic goitre and subsequently increase the incidence of thyroid nodules, global countries generally began to add a certain amount of iodine in their diet, mainly in salt. China began to implement the iodization policy of salt in 1995, and in 2011 the national iodine deficiency disease test results showed that iodine deficiency disorder (IDD) was being eliminated at the national level (1). The Shaanxi province was originally one of the provinces with the most serious iodine deficiency disease (2). After the implementation of the iodized salt policy, the iodine nutritional status in Shaanxi Province was at a slightly excessive level in 2011 (1). Shaanxi province has a salty diet, so this study can understand the current iodine content of people in Shaanxi Province, and provide a certain basis for further regulating the policy of iodized salt for people. In addition, there is still no conclusion on the relationship between iodine and thyroid disease, this study aimed to analyze the association between iodine intake level and thyroid diseases among adults in Shaanxi Province, and to explore whether iodine intake level is correlated with benign and malignant thyroid diseases. We present the following article in accordance with the STROBE reporting checklist (available at https://dx.doi. org/10.21037/atm-21-4928).

\section{Methods}

\section{Samples}

This study retrospectively analyzed the clinical data of patients with thyroid disease and healthy volunteers. Participants' basic information, urinary iodine (UI), and pathological reports were collected. Finally, a total of 1,159 patients with thyroid disease and 182 healthy volunteers were included in our study. All participants were aged $\geq 18$ years old, residents of Shaanxi Province, had been admitted to Xijing Hospital from January 2016 to December 2020, and agreed and signed informed consent. All participants with thyroid disease diagnosis underwent UI testing at the same time as the healthy volunteers, who for 2 weeks prior to testing did not consume any iodinecontaining substances that may have influenced the results, including drugs (amiodarone, compound iodine solution, or iodine-containing drugs) and excessive iodine-containing foods (kelp, seafood, and others). in addition, the healthy participants were not taking anti-thyroid drugs, and had no history of thyroid disease health check-up. According to the Chinese Guidelines for the Diagnosis and Treatment of Thyroid Diseases (3), the observation population was classified into the groups of hyperthyroidism, Hashimoto's thyroiditis (HT), papillary thyroid cancer (PTC), and the benign nodules, and those with disease whose morbidity was less than $10 \%$ of the total number of observers were grouped as others. All samples were confirmed by pathology. All procedures performed in this study involving human participants were in accordance with the Declaration of Helsinki (as revised in 2013). This study was approved by the ethics committee of the local hospital (Xijing hospital), and because it was a retrospective study, permission for the exemption of informed consent was obtained.

\section{Detection and evaluation of UI}

The UI content detection was conducted as follows: urine samples were collected randomly once during the day. The UI content was determined by arsenic-cerium catalytic spectrophotometry in WS/T 107-2006 standard issued by the Ministry of Health of China. Iodine intake status assessment method was based on the recommended method in the Guidelines for the Assessment of Iodine Deficiency Disorders and Their Elimination issued by the World Health Organization, UNICEF, and the Global Iodine Intake Alliance in 2001. Iodine intake assessment was based on UI: $<100 \mu \mathrm{g} / \mathrm{L}$, insufficient; $100-199 \mu \mathrm{g} / \mathrm{L}$, moderate; 200-299 $\mu \mathrm{g} / \mathrm{L}$, mild overdose; and >300 $\mu \mathrm{g} / \mathrm{L}$, excessive.

\section{Statistical analysis}

The chi-square test was used to compare the classified variables and continuous variables in the basic characteristics of participants. All confidence intervals (CIs) were stated at the $95 \%$ confidence level, non-normally distributed data were presented as median and quartile (P25, P75), and Kruskal-Wallis-H multi-group rank sum test was used for comparison between groups. A value of $\mathrm{P}<0.05$ was considered statistically significant. The software SPSS 19.0 (SPSS, Inc., Chicago, IL, USA) was used for data analysis.

\section{Results}

\section{Analysis of urinary iodine value}

A total of 1,341 patients [mean age $39.94 \pm 12.10$ years old, male 327 , female 1,014 , median urinary iodine (MUI) $233.20 \mu \mathrm{g} / \mathrm{L}$, range, 142.55 to 355.20 ], including 353 hyperthyroidism participants, 148 cases of HT, and 285 cases of PTC. There were 244 cases of benign thyroid nodules, 129 cases of other groups (hypothyroidism, thyroid 
Table 1 Comparison of urinary iodine (UI) $(\mu \mathrm{g} / \mathrm{L})$

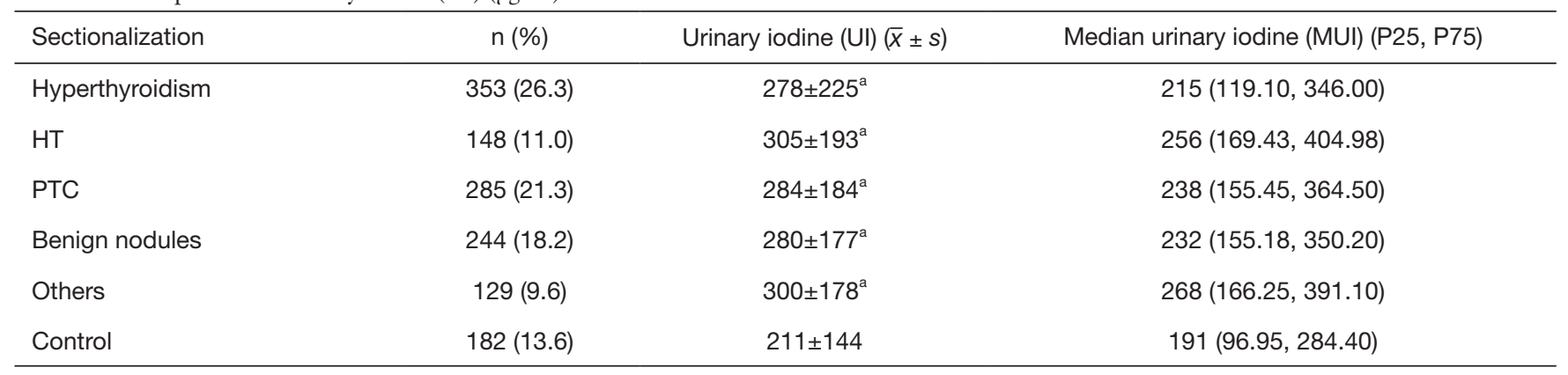

a, Kruskal-Wallis-H multi-group rank sum test, P<0.05. HT, Hashimoto's thyroiditis; PTC, papillary thyroid carcinoma; UI, urinary iodine; MUI, median urinary iodine.

tumor, thyroid cyst, and so on), and 182 cases in the control group. Compared with the control, there was statistical difference in UI in the hyperthyroidism, HT, PTC, benign nodules, and others $(\mathrm{P}<0.05)$ (Table 1$)$.

\section{Features of thyroid disease}

The odds ratio (OR) value of the group with insufficient iodine intake was 0.431 compared with that of the moderate iodine intake $(\mathrm{P}<0.05)$. The incidence of thyroid disease with excessive iodine intake was 1.55 times that in the moderate iodine intake $(\mathrm{P}=0.04)$. Compared with age $<45$ years and men, age $\geq 45$ years and women were risk factors for thyroid disease ( $\mathrm{OR}=1.59$ and 4.48, respectively) (Table 2).

\section{Comparison of thyroid nodule and PTC}

The correlation between iodine intake level, age, and gender in benign and PTC was compared, and the results showed no statistical difference $(\mathrm{P}>0.05)$ (Table 3). The OR value of the group with insufficient iodine intake was 0.423 compared with that of the moderate iodine intake group $(\mathrm{P}<0.05)$. The incidence of PTC in the overdose group was 1.595 times that in the moderate dose group $(\mathrm{P}=0.07)$. Compared with age $<45$ years and men, age $\geq 45$ years and women were risk factors for thyroid cancer $(\mathrm{OR}=1.84$ and 4.46, respectively) (Table 4).

\section{Features of benign thyroid disease}

Compared with moderate iodine intake, the prevalence of hyperthyroidism was decreased $(\mathrm{OR}=0.58, \mathrm{P}=0.03)$. When iodine intake was excessive, the morbidity of HT increased, and the OR value of HT was $2.36(\mathrm{P}<0.01)$ compared with the moderate group. The risk of benign nodules was shown to increase with age $\geq 45$ years old $(\mathrm{OR}=3.56, \mathrm{P}<0.01)$. In terms of gender, there were significant differences between men and women in thyroid diseases, with $\mathrm{P}<0.05$, indicating a statistical difference (Table 5).

\section{Discussion}

Iodine is an important synthetic raw material for the synthesis of thyroxine in the human body, which is closely related to human health. Both iodine deficiency and excess lead to thyroid diseases. Approximately $80-90 \%$ of human iodine comes from food, 10-20\% from drinking water, and $5 \%$ from air. About $5 \%$ is excreted through sweat glands, hair, and lungs. All the iodine absorbed by the human body is excreted except for a small portion (about 50-75 $\mu \mathrm{g}$ ) which is absorbed by the thyroid gland. Excess iodine is not stored in the body, and the kidneys are the main organ of iodine excretion (4). Therefore, UI can reflect the level of iodine intake to some extent.

This study found that the median of urinary iodine intake in Shaanxi Province was $233.20 \mu \mathrm{g} / \mathrm{L}$, which reflected a state of slight iodine overconsumption, consistent with the results of national iodine deficiency monitoring in 2011 (1). Compared with other regions in China, the level of UI in Shaanxi was higher, which may be related to the high-salt diet of people in Shaanxi. In this study, it was found that the incidence of thyroid diseases was lower when iodine intake was insufficient, which may be due to changes in the disease spectrum of thyroid diseases and the decline of thyroid diseases caused by iodine deficiency after the implementation of salt iodization policy for more than 10 years.

It was shown that hyperthyroidism patients had a higher 
Table 2 Thyroid disease compared with the control group

\begin{tabular}{|c|c|c|c|c|}
\hline Sectionalization & Thyroid disease & Control & OR $(95 \% \mathrm{Cl})$ & $P$ value \\
\hline Moderate & $329(28.4)$ & $48(26.4)$ & & \\
\hline Insufficient & $139(12.0)$ & $47(25.8)$ & $0.43(0.27$ to 0.67$)$ & $<0.01^{\mathrm{a}}$ \\
\hline Mild overdose & $264(22.8)$ & $47(25.8)$ & $0.82(0.53$ to 1.26$)$ & $0.36^{\mathrm{a}}$ \\
\hline \multicolumn{5}{|l|}{ Age, years, $\mathrm{n}(\%)$} \\
\hline$<45$ & $700(60.4)$ & $129(70.9)$ & & \\
\hline$\geq 45$ & $459(39.6)$ & $53(29.1)$ & 1.59 (1.13 to 2.24$)$ & $<0.01^{\mathrm{a}}$ \\
\hline \multicolumn{5}{|c|}{ Gender distribution, n (\%) } \\
\hline
\end{tabular}

a, chi-square test. OR, odds ratio; $\mathrm{Cl}$, confidence interval.

Table 3 The benign thyroid disease was compared with PTC

\begin{tabular}{|c|c|c|c|c|}
\hline Sectionalization & PTC & Benign thyroid & OR $(95 \% \mathrm{Cl})$ & $P$ value \\
\hline \multicolumn{5}{|c|}{ lodine intake $\mathrm{n}(\%)$} \\
\hline Moderate & $82(28.8)$ & 247 (28.3) & & \\
\hline Insufficient & 34 (11.9) & $105(12.0)$ & 0.97 (0.61 to 1.54$)$ & $0.91^{a}$ \\
\hline Mild overdose & $60(21.1)$ & $204(23.3)$ & 0.88 (0.60 to 1.29$)$ & $0.53^{\mathrm{a}}$ \\
\hline \multicolumn{5}{|l|}{ Age, years $\mathrm{n}(\%)$} \\
\hline$<45$ & $162(56.8)$ & $530(60.6)$ & & \\
\hline$\geq 45$ & $123(43.2)$ & $344(39.4)$ & 1.17 (0.89 to 1.53$)$ & $0.25^{\mathrm{a}}$ \\
\hline \multicolumn{5}{|c|}{ Sex distribution n (\%) } \\
\hline
\end{tabular}

${ }^{\text {a }}$, chi-square test. PTC, papillary thyroid cancer, OR, odds ratio; $\mathrm{Cl}$, confidence interval.

UI level than the normal control group, indicating that excessive iodine intake is a risk factor for hyperthyroidism, with some researchers asserting that long-term excessive iodine intake will lead to increased hyperthyroidism (5-10). The thyroid has a certain capacity for adjustment, within a certain range of iodine deficiency or iodine excess normal thyroid function can be maintained; when iodine intake exceeds the adaptive capacity of the thyroid, some people will manifest disease, with hypothyroidism may occur due to the thyroid losing its inhibitive ability (11), "researches has been shown that when iodine intake is excessive, it is mainly manifested as iodine detoxification dysfunction, which leads to an increase in the prevalence of hypothyroidism $(12,13)$ "; this is consistent with the results of this study. However, another expert has proposed that iodine intake has nothing to do with the incidence of hyperthyroidism. In the 3 different areas of Panshan (mild iodine deficiency areas), Zhangwu (abundant iodine area), Huanghua (iodine excess areas), a 5-year prospective epidemiological study of thyroid disease researched by Teng Xiao-chun found that the areas 
Table 4 The PTC was compared with the control

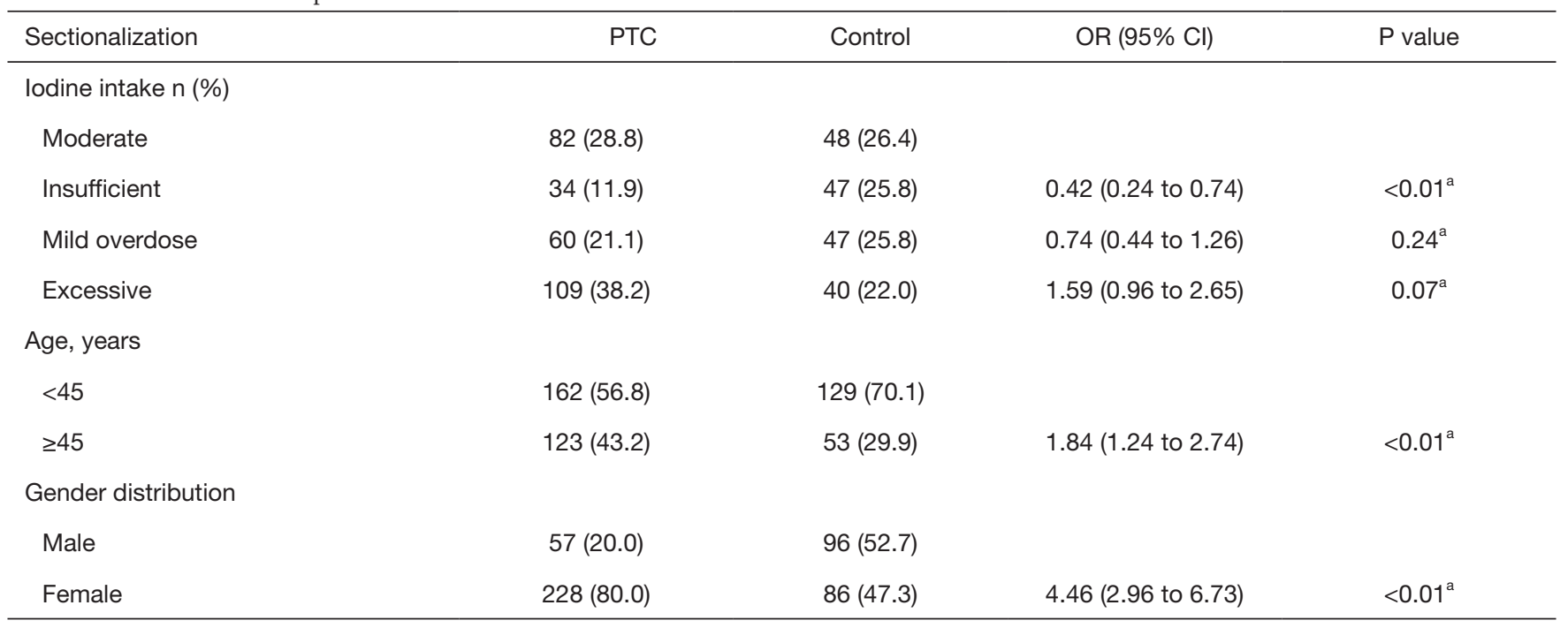

a, chi-square test. PTC, papillary thyroid cancer; OR, odds ratio; $\mathrm{Cl}$, confidence interval.

Table 5 Hyperthyroidism, HT, and benign nodules compared with the control

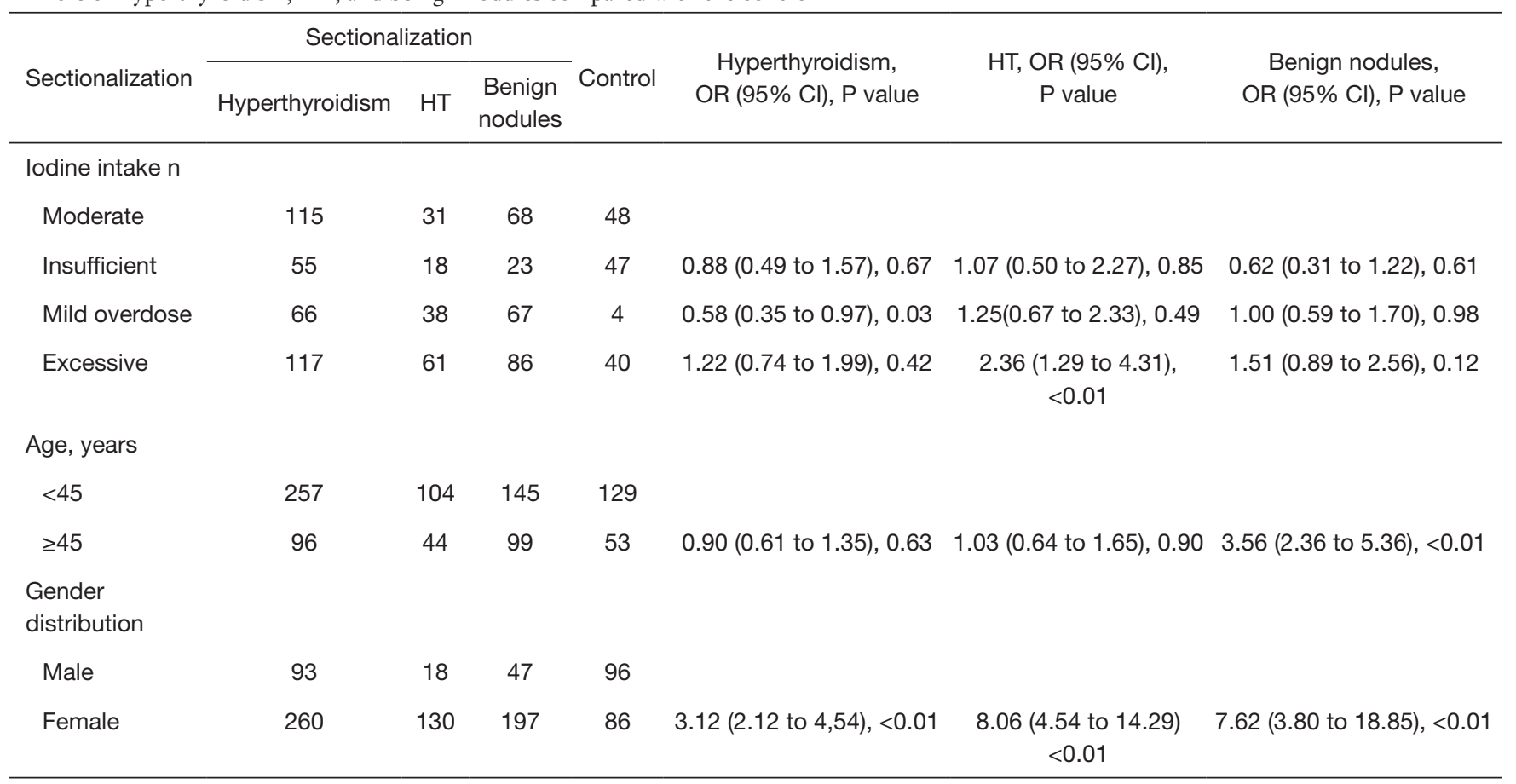

HT, Hashimoto's thyroiditis; OR, odds ratio; $\mathrm{Cl}$, confidence interval.

had no statistically significant differences compared with hyperthyroidism prevalence and incidence of a disease (14).

Some animal studies have found that the thyroid has a stronger tolerance to iodine excess than iodine deficiency (15), which may be the reason why the prevalence and morbidity of hyperthyroidism does not increase when iodine intake is excessive. The increase of iodine intake will lead to changes in the spectrum of thyroid diseases. Yan et al. found that the incidence of thyroid nodules increases in areas with high iodine levels (16). An epidemiological study conducted by 
Shan et al. (17) showed a significant rise in the incidence of thyroid nodules in areas with iodine excess $(\mathrm{P}=0.001)$, which is consistent with the results of this study. The increase of iodine intake will also lead to growth in the incidence of HT. Epidemiological investigations conducted by Teng et al., Shan et al., and other scholars have confirmed this view $(13,18)$. Part of the reason for HT due to high iodine may be that high iodine thyroxine is more immunogenic (19).

In this study, participants with thyroid cancer had higher UI levels than those in the control group $(\mathrm{P}<0.05)$, and the incidence of PTC was 1.595 times higher when iodine intake was greater than moderate. Guan et al. (20) found that the incidence of thyroid cancer in a high iodine area was significantly increased compared with other areas $(\mathrm{P}<0.01)$, when comparing the incidence of thyroid diseases in high iodine areas, low iodine areas, and suitable iodine areas. However, a survey conducted on iodine-rich and iodine-poor areas in Italy found that the incidence of thyroid cancer in iodine-poor areas was 2-3 times higher than that in iodine-rich areas (21). However, surveys in Iceland (22) and Hawaii (23) have shown that thyroid cancer levels remain quite high (well above the average incidence). An investigation of 2 iodine-poor and iodinerich areas in eastern and western Denmark did not show a significant difference in the incidence of thyroid cancer (24). The relationship between iodine intake and thyroid cancer remains unclear, but the results of this study suggest that excess iodine intake is associated with PTC.

In this study, the comparison of UI between malignant thyroid disease and benign thyroid disease showed that there was no statistical difference in UI. Liu et al. (25) also held the same view, but some researchers have shown that UI is higher in malignant thyroid disease than in benign disease (26). The results of this study showed a clear correlation between gender and the incidence of thyroid disease, with an incidence ratio of 1:4.484. We speculated that the reason for this may be due to the levels of various hormones, mental physiological environment of males and females, or that women paying more attention to their health leads to a higher detection rate. Among the thyroid disease participants in this study, the incidence of thyroid disease in those older than 45 years was 1.514 times that of those younger than 45 years. The risk of PTC increased with age. At this stage, the crowd of iodine on the high side, this with our ten years of iodized salt policy is by the relationship, we should pay more attention to individual iodized salt policy. we can test our urinary iodine in the relevant inspection agencies, to judge our own iodine situation by the doctor, make us appropriately increase or decrease the iodine intake, and regular check, keeping our iodine intake at the moderate level can reduce the risk of thyroid disease to some extent.

This study reviewed thyroid disease-related research conducted in Xijing hospital in the recent 5 years to roughly reflect the current level of iodine nutrition in Shanxi Province, and it was found to belong to the super sufficient condition category. The occurrence of thyroid disease may be associated with high iodine intake, which may have a unique impact on thyroid disease. We believe that iodine supplementation should follow scientifically individualized strategy.

\section{Acknowledgments}

Funding: Health Research Fund of Shaanxi Province (CATEGORY D); Project Number: 2018D070.

\section{Footnote}

Reporting Checklist: The authors have completed the STROBE reporting checklist. Available at https://dx.doi. org/10.21037/atm-21-4928

Data Sharing Statement: Available at https://dx.doi. org/10.21037/atm-21-4928

Conflicts of Interest: All authors have completed the ICMJE uniform disclosure form (available at https://dx.doi. org/10.21037/atm-21-4928). The authors have no conflicts of interest to declare.

Ethical Statement: The authors are accountable for all aspects of the work in ensuring that questions related to the accuracy or integrity of any part of the work are appropriately investigated and resolved. All procedures performed in this study involving human participants were in accordance with the Declaration of Helsinki (as revised in 2013). This study was approved by the ethics committee of the local hospital (Xijing hospital), and because it was a retrospective study, permission for the exemption of informed consent was obtained.

Open Access Statement: This is an Open Access article distributed in accordance with the Creative Commons Attribution-NonCommercial-NoDerivs 4.0 International 
License (CC BY-NC-ND 4.0), which permits the noncommercial replication and distribution of the article with the strict proviso that no changes or edits are made and the original work is properly cited (including links to both the formal publication through the relevant DOI and the license). See: https://creativecommons.org/licenses/by-nc-nd/4.0/.

\section{References}

1. Liu P, Su X H, et al. Analysis of surveillance results of iodine deficiency disease in China in 2011. Chinese Journal of Endemiology 2015;34:181-5.

2. Chen J, Li Z, Xu H, et al. Iodine deficiency disease in China. Beijing: People's Medical Publishing House, 1999:7.

3. Guidelines for the diagnosis and treatment of thyroid diseases in China. Available online: https://max.book118. $\mathrm{com} / \mathrm{html} / 2020 / 0704 / 8046061063002122 . s h t m$

4. Chen ZP. Measurement of urinary iodine and its clinical significance. Chin J Endocrinol 1997;16:35-7.

5. Foppiani L, Cascio C, Lo Pinto G. Iodine-induced hyperthyroidism as combination of different etiologies: an overlooked entity in the elderly. Aging Clin Exp Res 2016;28:1023-7.

6. Huang Q, Jin R, Zou D, et al. Changes in the incidence of thyroid disease after increased iodine intake. Chin J epidemiol 2001;22:455-8.

7. Li Y, Teng D, Ba J, et al. Efficacy and Safety of LongTerm Universal Salt Iodization on Thyroid Disorders: Epidemiological Evidence from 31 Provinces of Mainland China. Thyroid 2020;30:568-79.

8. Ji L, Shen C, Yang G, et al. Relationship between iodine and thyroid disease. Chin J Endol Dis 2020;35:120-3.

9. Sarfo-Kantanka O, Kyei I, Sarfo FS, et al. Thyroid Disorders in Central Ghana: The Influence of 20 Years of Iodization. J Thyroid Res 2017;2017:7843972.

10. Deng F, Zhong W, Dai C, et al. Effect of salt iodization on thyroid disease in Guangdong coastal area with mild iodine deficiency. South China Preventive Medicine 2007;33:1-6.

11. Bai Yao. Thyroidology: basic and clinical implications. Beijing: Beijing Scientific and Technical Literature Press 2003:153, 244-254, 620-628.

12. Pei H, Zhou Y, Zhang Q, et al. The prevalence of hypothyroidism in the population with iodine overdose. Chinese Journal of Endemiology 2007;26:669-672.

13. Shan Z, Teng W, Li Y, et al. An epidemiological study of iodine induced hypothyroidism. Chin J endocrinol 2001;17:71-4.
14. Teng X, Teng D, Shan Z, et al. A 5-year prospective epidemiological study of the effect of increased iodine intake on thyroid disease. Chinese Journal of Endocrinology and Metabolism 2006;22:512-7.

15. Chen $Z$, Yan $Y, X$, et al. Iodine deficiency and iodine excess in rats: a comparative study. Chinese Journal of Endemiology 2005;24:242-4.

16. Yan YR, Liu Y, Huang H, et al. Iodine nutrition and thyroid diseases in Chengdu, China: an epidemiological study. QJM 2015;108:379-85.

17. Shan Z, Chen L, Lian X, et al. Iodine Status and Prevalence of Thyroid Disorders After Introduction of Mandatory Universal Salt Iodization for 16 Years in China: A CrossSectional Study in 10 Cities. Thyroid 2016;26:1125-30.

18. Teng $W$, Shan $Z$, Teng $X$, et al. Effect of iodine intake on thyroid diseases in China. N Engl J Med 2006;354:2783-93.

19. Rayman MP. Multiple nutritional factors and thyroid disease, with particular reference to autoimmune thyroid disease. Proc Nutr Soc 2019;78:34-44.

20. Guan H, Teng W, Yang S. Comparative epidemiological study on thyroid cancer in areas with different iodine intakes. Zhonghua Yi Xue Za Zhi 2001;81:457-8.

21. Belfiore A, La Rosa GL, Padova G, et al. The frequency of cold thyroid nodules and thyroid malignancies in patients from an iodine-deficient area. Cancer 1987;60:3096-102.

22. Williams ED, Doniach I, Bjarnason O, et al. Thyroid cancer in an iodide rich area: a histopathological study. Cancer 1977;39:215-22.

23. Goodman MT, Yoshizawa CN, Kolonel LN. Descriptive epidemiology of thyroid cancer in Hawaii. Cancer 1988;61:1272-81.

24. Sehestedt T, Knudsen N, Perrild H, et al. Iodine intake and incidence of thyroid cancer in Denmark. Clin Endocrinol (Oxf) 2006;65:229-33.

25. Liu L, Li Y, Zheng X, et al. Urinary iodine detection and clinical analysis of thyroid tumor patients in tianjin. Chin J Clin Oncol 2011;38:24-7.

26. Zhang Y, Xie P, Ding J, et al. Iodine and common thyroid diseases correlation study. Chinese Journal of Cancer Prevention and Treatment 2015;22:687-691.

Cite this article as: Yu Z, Yu Y, Wan Y, Fan J, Meng H, Li S, Wang $\mathrm{Y}$, Wang T, Ling R. Iodine intake level and incidence of thyroid disease in adults in Shaanxi province: a cross-sectional study. Ann Transl Med 2021;9(20):1567. doi: 10.21037/atm-214928 